\title{
Molecular characterisation of four cases of intrachromosomal triplication of chromosome $15 \mathrm{q} 11-\mathrm{q} 14$
}

Paola Ungaro, Susan L Christian, Judy A Fantes, Apiwat Mutirangura, Susan Black, James Reynolds, Sue Malcolm, William B Dobyns, David H Ledbetter Context-Chromosomal abnormalities that involve the proximal region of chromosome $15 q$ occur relatively frequently in the human population. However, interstitial triplications involving one 15 homologue are very rare with three cases reported to date. Objective-To provide a detailed molecular characterisation of four additional patients with interstitial triplications of chromosome 15q11-q14. Design-Molecular analyses were per-
formed using DNA markers and probes specific for the 15q11-q14 region. Setting-Molecular cytogenetics laboratory at the University of Chicago. Subjects-Four patients with mild to severe mental retardation and features of Prader-Willi syndrome (PWS) or Angelman syndrome (AS) were referred for ation of a suspected duplication/ chromosome 15q11-q14 by routine cytogenetic analysis.

Main outcome measures-Fluorescence in situ hybridisation (FISH) was performed to determine the type of chromosomal abnormality present, the extent of the abnormal region, and the orientation of the extra chromosomal segments. Molecular polymorphism analysis was performed to determine the parental origin of the abnormality. Methylation and northern blot analyses of the SNRPN gene were performed to determine the effect of extra copies of the SNRPN gene on its methylation pattern and expression. Results-Fluorescence in situ hybridisation (FISH) using probes within and flanking the Prader-Willi/Angelman syndrome critical region indicated that all patients carried an intrachromosomal triplication of proximal 15q11-q14 in one of the two chromosome 15 homologues (trip(15)). In all patients the orientation of the triplicated segments was normalinverted-normal, suggesting that a common mechanism of rearrangement may have been involved. Microsatellite analysis showed the parental origin of the trip(15) to be maternal in three cases and paternal in one case. The paternal triplication patient had features similar to PWS, one maternal triplication patient had features similar to AS, and the other two maternal triplication patients had non-specific findings including hypotonia and mental retardation. Methylation analysis at exon 1 of the SNRPN locus showed increased dosage of either the paternal or maternal bands in the paternal or maternal triplication patients, respectively, suggesting that the methylation pattern shows a dose dependent increase that correlates with the parental origin of the triplication. In addition, the expression of SNRPN was analysed by northern blotting and expression levels were consistent with dosage and parental origin of the triplication. Conclusions-These four additional cases of trip(15) will provide additional information towards understanding the phenotypic effects of this abnormality and aid in understanding the mechanism of formation of other chromosome 15 rearrangements.

(F Med Genet 2001;38:26-34)

Keywords: chromosome 15 triplication; Prader-Willi syndrome; Angelman syndrome; autism

The proximal long arm of human chromosome 15 is frequently involved in molecular rearrangements including deletions, ${ }^{1}$ duplications, ${ }^{2}$ triplications, ${ }^{3-5}$ translocations, ${ }^{6}$ and inversions, ${ }^{7}$ as well as in the formation of supernumerary marker chromosomes. ${ }^{89}$ Approximately $70 \%$ of patients with Prader-Willi syndrome (PWS) or Angelman syndrome (AS) can be characterised by the presence of a de novo interstitial deletion of 15q11-q13 spanning approximately $4 \mathrm{Mb}^{10}{ }^{11}$ This recurring deletion is one of the most common observed in humans and identifies at least three hotspots for chromosome breakage in the 15q11-q13 region, referred to as $\mathrm{BP} 1, \mathrm{BP} 2$, and $\mathrm{BP} 3 .{ }^{12-16}$ Whether this deletion results in PWS or AS depends upon the origin of the affected homologue (paternal or maternal, respectively). This parent of origin effect is the result of the presence of oppositely imprinted gene(s) within the 15q11-q13 region. ${ }^{17}$

Interstitial duplications of 15q11-q13 of maternal origin have been identified in patients with developmental delay/learning difficulties ${ }^{2}$ and patients with autistic behaviour. ${ }^{18-20}$ Subjects with paternally derived duplications have a normal phenotype instead. ${ }^{219}$ The duplications frequently cover the entire PWS/AS critical region. ${ }^{211} 1921$ The distal extent of two maternal duplications has been mapped be- 
tween S12 and S24, the site of BP3, while the proximal breakpoint is at $\mathrm{BP} 2 .{ }^{21}$ The data from these two cases would suggest that the interstitial duplications may be reciprocal products of the interstitial deletion events. ${ }^{21}$

Interstitial triplication of $15 \mathrm{q} 11-\mathrm{q} 13$ has been previously reported in only three patients. Triplications of either maternal or paternal origin present with an abnormal phenotype and significant developmental delay as the most common phenotypic features. ${ }^{3-5}$ The distal extent of two triplication cases has been determined to lie distal to $\mathrm{S} 1043$, while the proximal extent is unknown. ${ }^{11}$

In addition to interstitial triplications, tetrasomy of the PWS/AS critical region is observed in patients with a large supernumerary pseudodicentric chromosome 15, commonly referred to as an "inverted duplication of chromosome 15" (inv dup(15)). Inv dup(15) chromosomes occur with a frequency of $1 / 5000$ live births ${ }^{22}$ and are classified into two major groups, small inv dup(15) chromosomes, which do not contain the PWS/AS critical region, ${ }^{815}$ and large inv $\operatorname{dup}(15)$ chromosomes, that usually contain two extra copies of the PWS/AS critical region. ${ }^{8}$ While the small inv dup(15) chromosomes are usually associated with a normal phenotype, patients with the large inv dup(15) chromosomes present with mental retardation, abnormal electroencephalogram (EEG), epilepsy, hypotonia, poor motor coordination, and other dysmorphic features. ${ }^{23} 24$ The proximal breakpoint regions (BP1 and BP2) found in PWS/AS patients are also involved in the formation of the small inv dup(15) chromosomes. ${ }^{15}$ The distal boundary of the large inv dup(15) chromosomes apparently involves four different breakpoints, one equivalent to the common deletion breakpoint region of the PWS/AS patients (BP3), one located between $G A B R B 3$ and D15S12, and the other two distal to D15S1043. ${ }^{911}$

Here we describe four patients with an interstitial triplication of 15q11-q14 associated with developmental delay. In each case we examined the extent, the orientation, and the parental origin of the triplicated segment and the effects on methylation and expression of the SNRPN gene.

\section{Case reports}

The clinical findings associated with these patients are summarised in table 1 and are compared to other cases with molecularly characterised triplications.
PATIENT 1

The clinical history of this girl has been previously described (patient 2) by Pettigrew et al. ${ }^{25}$ She showed many features of the Prader-Willi syndrome such as mental retardation, obesity, compulsive eating, small hands and feet, and short stature. The external genitalia appeared normal. Menarche occurred at the age of 12 with irregular periods.

\section{PATIENT 2}

This girl was previously reported by ClaytonSmith et al. ${ }^{26}$ Briefly, she had language delay with poor vocalisation and no recognisable words at 2 years of age. She could say some single words at the age of 4 years. At 6 years of age she showed global developmental delay functioning at a 3 year old level. On examination, she had a wide based, ataxic gait and difficulty with gross motor coordination. These clinical features are usually seen to a more severe degree in Angelman syndrome. An EEG and CT scan were both normal.

\section{PATIENT 3}

This boy was born to a healthy, 25 year old mother and 28 year old father who were non-consanguineous and also had a normal daughter. Decreased fetal movements were noticed during pregnancy. Vaginal delivery at 40 weeks was uncomplicated with a birth weight of $3500 \mathrm{~g}$ and length of $51 \mathrm{~cm}$. Apgar scores were 8 and 9 after one and five minutes, respectively. From infancy, he had generalised hypotonia and delayed milestones, smiling at six months and standing at 16 months. Eye examination at 2 months showed poor visual tracking, strabismus, and a normal retina. EEG and brain MRI at 2 months were normal. At 4 months, detailed audiological examinations performed because of non-responsiveness to acoustic stimuli were normal. General and neurological examination was otherwise unremarkable.

PATIENT 4

This girl is the daughter of two healthy, non-consanguineous parents. Pregnancy and delivery, at 40 weeks, were uncomplicated with a birth weight of $3400 \mathrm{~g}$. Developmental milestones were globally delayed with walking at 20 months and use of single words by 22 months. Clinical examination at 22 months showed length $82 \mathrm{~cm}$ (10th centile), weight $9.75 \mathrm{~kg}$ ( 3 rd centile), OFC $45.3 \mathrm{~cm}$ ( 3 rd centile), ICD $2.8 \mathrm{~cm}$ (75th centile), palpebral fissure length $2.4 \mathrm{~cm}$ (25th-50th centile), ear height $4.8 \mathrm{~cm}$ (25th-50th centile), hand length $9 \mathrm{~cm}$ (3rd centile). She had brachycephaly, a round face

Table 1 Summary of patients with intrachromosomal 15q11-q14 triplication

\begin{tabular}{|c|c|c|c|c|c|}
\hline Patient & $\begin{array}{l}\text { Sex and age of } \\
\text { patient }\end{array}$ & Phenotype & $\begin{array}{l}\text { Extent of triplication (probe } \\
\text { order in fig 1) }\end{array}$ & $\begin{array}{l}\text { Middle repeat } \\
\text { inverted }\end{array}$ & Parental origin \\
\hline Patient 1 , see also ref 25 & $\mathrm{~F}, 12 \mathrm{y}$ & Mild mental retardation, cleft palate, obesity & D15S18-D15S1019 & Yes & Paternal \\
\hline Patient 2 , see also ref 26 & $\mathrm{~F}, 6 \mathrm{y}$ & Ataxia, mild mental retardation, speech delay & D15S11-D15S165 & Yes & Maternal \\
\hline Patient 3 & $\mathrm{M}, 7 \mathrm{mth}$ & Severe mental retardation, generalised hypotonia, strabismus & D15S18-D15S1019 & Yes & Maternal \\
\hline Patient 4 & $\mathrm{~F}, 24 / 12 \mathrm{y}$ & $\begin{array}{l}\text { Severe mental retardation, mild hypotonia, strabismus, } \\
\text { brachycephaly }\end{array}$ & D15S18-D15S165 & Yes & Maternal \\
\hline $\operatorname{Ref} 4,11$ & $\mathrm{~F}, 7 \mathrm{y}$ & Mental retardation, hypotonia, seizure, autistic features & D15S18-D15S1043 & Yes & Maternal \\
\hline Ref 5 & $\mathrm{~F}, 4 \mathrm{y}$ & Developmental delay, seizure, ataxia & D15S18-D15S24 & Yes & Maternal \\
\hline Ref 3,11 & $\mathrm{~F}, 6 \mathrm{y}$ & Developmental delay, hypotonia & ?-D15S1043 & - & Paternal \\
\hline
\end{tabular}




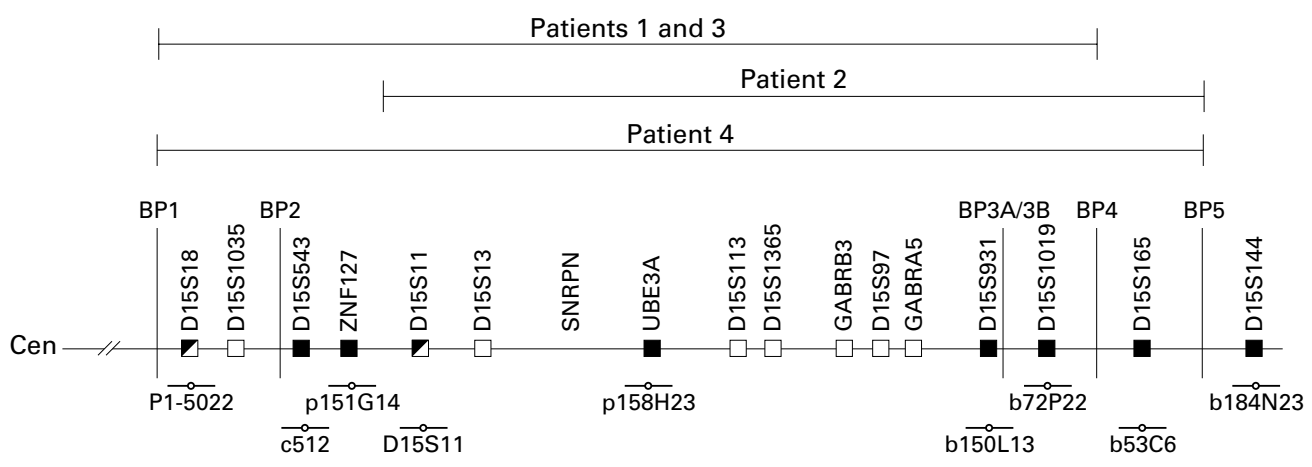

- Tested by FISH

$\square$ Tested by PCR

Tested by FISH and PCR

Figure 1 Schematic representation of the physical map of 15q11-q14 (not to scale) showing the relative positions of probes and primers used in FISH and PCR analyses. ${ }^{10} 1516$ BP1, BP2, and BP3 are the three hotspots for chromosomal deletion, the breakpoints found between S1019 and S165 and between S165 and S144 are indicated as BP4 and BP5, respectively.

with a short forehead and mild frontal bossing, extension of the temporal hairline to the lateral eyebrows, mild synophrys, bilateral inner epicanthic folds, slightly upward slanting palpebral fissures, myopia, strabismus, broad nasal bridge and upturned nares, slightly small jaw, normal position of the ears with midhelical hypoplasia, mild hypertrichosis of the back, mild swelling of the dorsa of both hands and feet, and slightly tapering fingers. Neurological examination showed only mild hypotonia.

\section{Materials and methods}

CYTOGENETICS AND FISH ANALYSIS

Cytogenetic analysis was performed on peripheral blood lymphocyte cultures from patients 3 and 4 and their parents using standard techniques. Preparations were GTG stained. For analysis of patients 1 and 2 see Pettigrew et $a l^{5}$ and Clayton-Smith et $a l^{26}$

Lymphoblastoid cell lines were established for each patient and chromosome preparations were made from these cells using standard methods. The probes used in these studies are listed in order from proximal to distal where $\mathrm{P} 1=\mathrm{P} 1$ clone, $\mathrm{b}=\mathrm{BAC}, \mathrm{p}=\mathrm{PAC}$, and $\mathrm{c}=$ cosmid: P1-5022 (D15S18), c512 (D15S543), p151G14 (ZNF127), D15S11, p158H23 (UBE3A), b150L13 (D15S931), b72P22 (D15S1019), b53C6 (D15S165), b184N23 (D15S144). All BACs, PACs, and P1 clones were acquired from Genome Systems Inc ( $\mathrm{St}$ Louis, MO). p158H23 (UBE3A) was kindly provided by Dr James S Sutcliffe. D15S11 was acquired as a commercially available FISH probe (Oncor, now Vysis Inc, Downer's Grove, IL). DNA from genomic clones was isolated using an AutoGen 740 (Integrated Separation System, Natick, MA). Each clone was labelled by nick translation and hybridised as previously described. ${ }^{27}$ FISH slides were analysed using a Zeiss Axiophot microscope with filters for separate detection of DAPI, FITC, and rhodamine as well as a triple bandpass filter (No 83000, Chroma Technology, Brattleboro, VT) to detect signals simultaneously. Images were collected and merged using a cooled CCD camera (KAF 1400, Photometrics, Tucson,
AZ) and IP Lab Spectrum (Signal Analytics, Vienna, VA) or Quips mFISH software (Vysis, Downer's Grove, IL). The relative positions of the probes are shown in fig $1 .^{1015} 1628$

MOLECULAR POLYMORPHISM ANALYSIS

Genomic DNA of the patients and their parents was prepared either directly from peripheral blood lymphocytes (parents) or from Epstein-Barr virus transformed lymphoblastoid cell lines (patients). Nine short tandem repeat polymorphic markers (STRs) inside the PWS/AS region were used to determine the parental origin of the triplicated chromosome, as previously described. ${ }^{10}$ The locations of the polymorphic markers used in this analysis are shown in fig 1. Polymerase chain reaction (PCR) assays were carried out using published methods. ${ }^{29} \mathrm{PCR}$ products were separated on a $6 \%$ polyacrylamide/urea gel and visualised by autoradiography.

\section{METHYLATION ANALYSIS}

SNRPN exon 1 methylation analysis was performed using a methylation specific PCR assay (M-PCR), described previously, ${ }^{30}$ with the addition of $0.15 \mu \mathrm{l}$ of $\alpha-\left[{ }^{32} \mathrm{P}\right] \mathrm{dCTP} / \mathrm{sample}$. Radiolabelled PCR products were separated on an $8 \%$ acrylamide gel and maternal (174 bp) and paternal (100 bp) bands were quantified using a phosphorimager with ImageQuaNT software (Molecular Dynamics, Sunnyvale, CA, USA). The ratio of the area under the curve of the maternal band relative to that of the paternal band and vice versa was determined for a control subject with a normal karyotype and for the four patients. The values obtained for the patients were then compared to the normal control.

\section{NORTHERN ANALYSIS}

Total RNA was purified using TRIzol Reagent from Life Technologies Inc (Rockville, MD). Twenty $\mu \mathrm{g}$ of total RNA were loaded in each lane for northern blot analysis. A cDNA probe for the $S N R P N$ region exon -1 to exon 1 (RN175, RN140) was generated as previously described. $^{31}$ The PCR product was cloned 
using a pGEM-T Easy vector (Promega Madison, WI, USA) and was ${ }^{32}$ P-labelled by random priming. ${ }^{32}$ Hybridisation was performed using ExpressHyb Solution (Clontech, Palo Alto, CA, USA) at $65^{\circ} \mathrm{C}$. The filters were washed in a solution of $0.2 \times \mathrm{SSC}, 0.1 \% \mathrm{SDS}$ at $65^{\circ} \mathrm{C}$. An oligonucleotide specific for $28 \mathrm{~S}$ ribosomal RNA (5'-AACGATCAGAGTAGTGGTATTTCACC $-3^{\prime}$ ) was directly ${ }^{32} \mathrm{P}$-labelled and used to correct for RNA loading differences. ${ }^{33}$ Relative intensities of the hybridised bands were quantified using ImageQuaNT software.

\section{Results}

EXTENT OF THE TRIPLICATED SEGMENTS

$G$ banding analysis of patient 1 and patient 2 was previously reported and originally interpreted as indicating interstitial duplications. ${ }^{25} 26$ $\mathrm{G}$ banding analysis of patient 3 and patient 4 showed a 46,XX,15q+ karyotype that was also initially interpreted as probable duplication of the 15q11-q13 region (data not shown).

Dual colour FISH analysis using combinations of clones P1-5022, p158H23, b72P22, b53C6, or b184N23 was performed on inter-
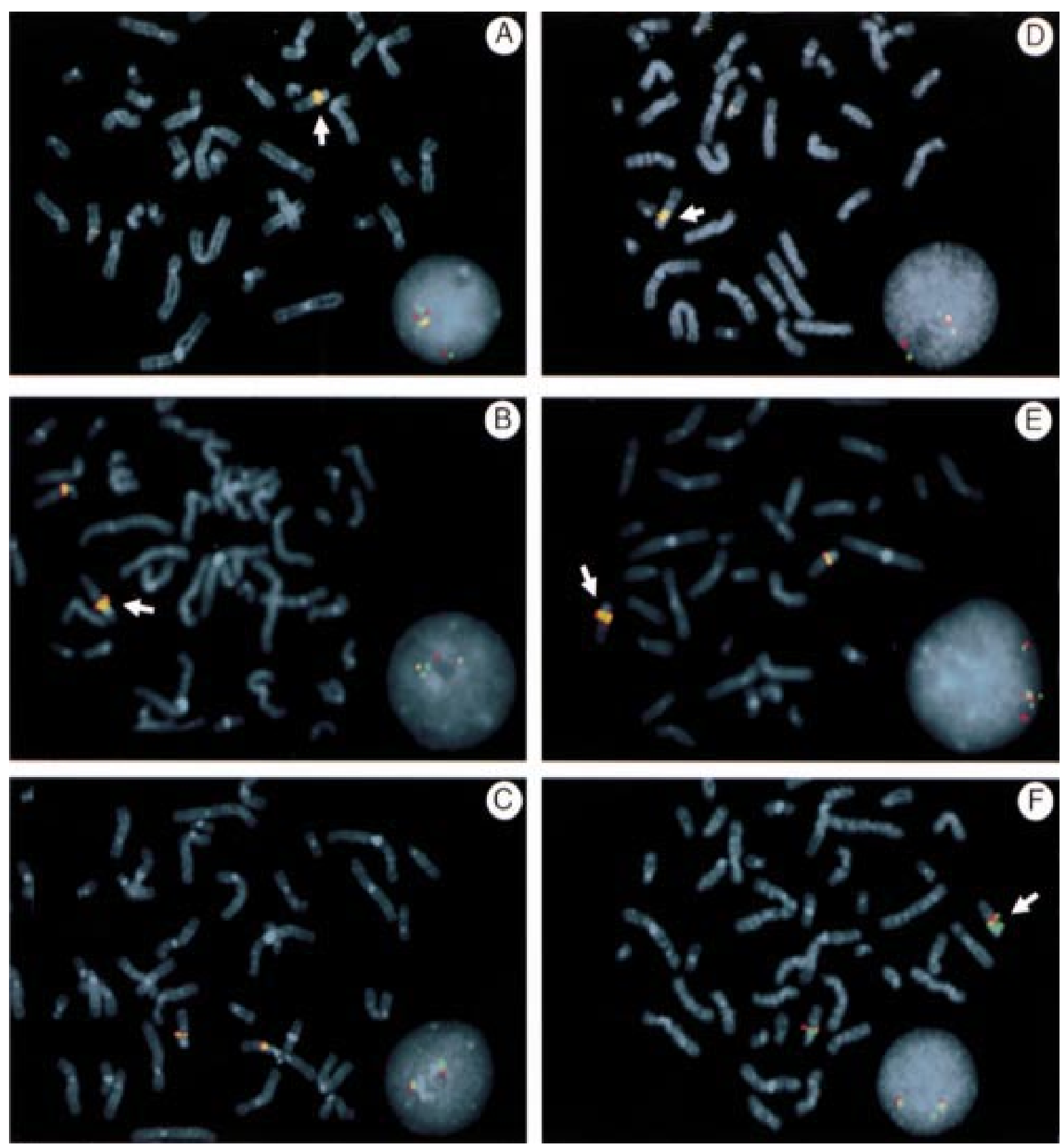

Figure 2 FISH showing normal and triplicated signals on chromosome 15. (A, B, C) Metaphase cells and interphase nuclei from patient 1 showing that the triplication extends from BP1 to BP4; the abnormal 15 (arrow) has three copies of P1-5022 (D15S18, red) and of p158H23 (UBE3A, green) (A) and three copies of p158H23 (green) and b72P22 (D15S1019, red) (B). Probes b53C6 (D15S165, green) and b184N23 (D15S144, red) are both present in single copies $(C)$. $(D, E, F)$ Metaphase cells and interphase nuclei from patient 4 showing that the triplication extends from BP1 to BP5; the abnormal 15 (arrow) shows three copies of P1-5022 (D15S18, red) and of p158H23 (UBE3A, green) (D), three copies of p158H23 (green) and of b72P22 (D15S1019, red) (E), and three copies of b53C6 (D15S165, green) but only one copy of b184N23 (D15S144, red) (F). 

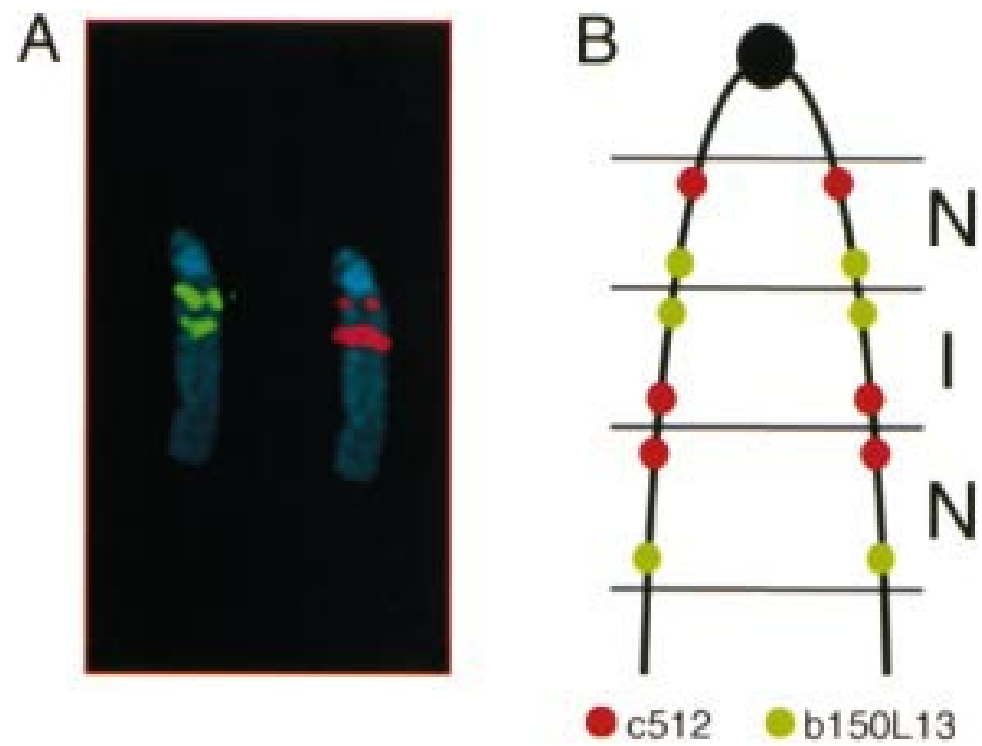

Figure 3 Orientation of the triplicated segments. Hybridisation with probes $c 512$ (red) and b150L13 (green) to metaphase chromosomes of patient $4(A)$ and ideogram of the triplicated chromosome 15 showing the relative position of the probes used (B). For probe c512 (red) the telomeric signal was of double intensity as compared to the centromeric signal; for probe b150L13 (green) the centromeric signal was stronger than the telomeric signal, indicating that the repeats of the triplication are normal $(N)$ in the proximal and distal regions and inverted (I) in the central region. The same results were obtained in patients 1 , 2, and 3. Note that in patient 2, c512 was replaced by D15S11 as proximal probe.

phase nuclei and metaphase chromosomes. The locations of these clones within chromosome $15 \mathrm{q} 11$-q14 are presented in fig 1 . Patient
1 (fig 2A-C) and patient 3 showed identical results, including three signals on one chromosome 15 homologue for probes P1-5022, p $158 \mathrm{H} 23$, and b72P22, and a single signal for clones b53C6 and b184N23. This indicates that these patients have triplications extending from a site proximal of $S 18$ to a point between S1019 and S165 (fig 1). Patient 4 (fig 2D-F) showed three signals for clones P1-5022, $\mathrm{p} 158 \mathrm{H} 23$, and $\mathrm{b} 72 \mathrm{P} 22$ as well as for clone b53C6, while only clone b184N23 was present in single copy. This larger triplication, therefore, includes both S18 and S165 (fig 1). These results indicate that in these three patients the triplicated region extends from the most proximal breakpoint, BP1, to a distal breakpoint that lies between D15S1019 and D15S165 in patients 1 and 3 (BP4), and S15S165 and D15S144 in patient 4 (BP5) (fig 1).

FISH analysis using the same clones on interphase nuclei and metaphase chromosomes of patient 2 also showed three signals using clones $\mathrm{p} 158 \mathrm{H} 23, \mathrm{~b} 72 \mathrm{P} 22$, and b53C6, indicating that the distal extent of the triplication in patient 2 is the same as that in patient 4 (BP5) (fig 1). The proximal breakpoint in this patient, however, involves a previously unobserved breakpoint that was mapped using clones c512, p151G14, and D15S11. These results indicate that in patient 2 the proximal breakpoint lies between ZNF127 and D15S11 (fig 1).
A
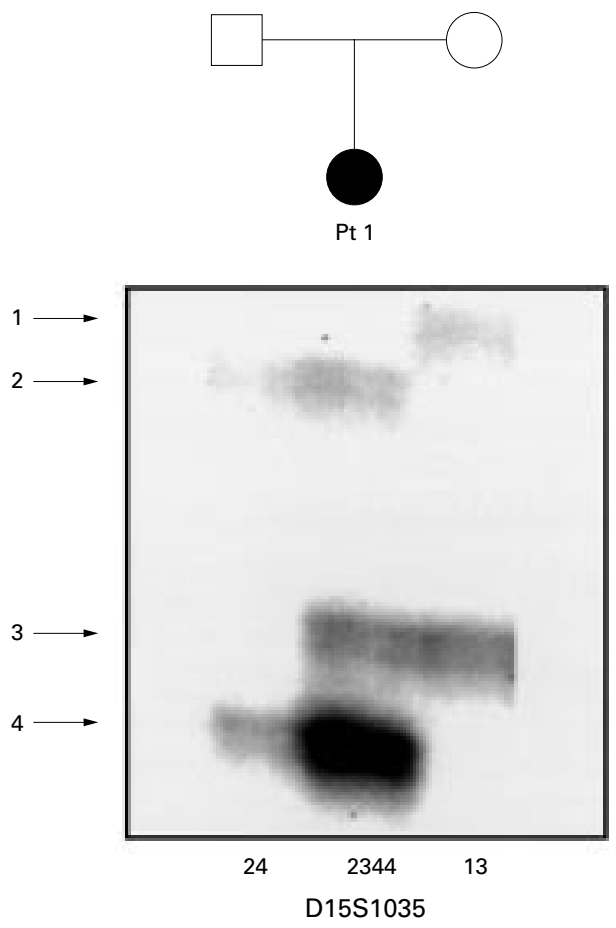

B
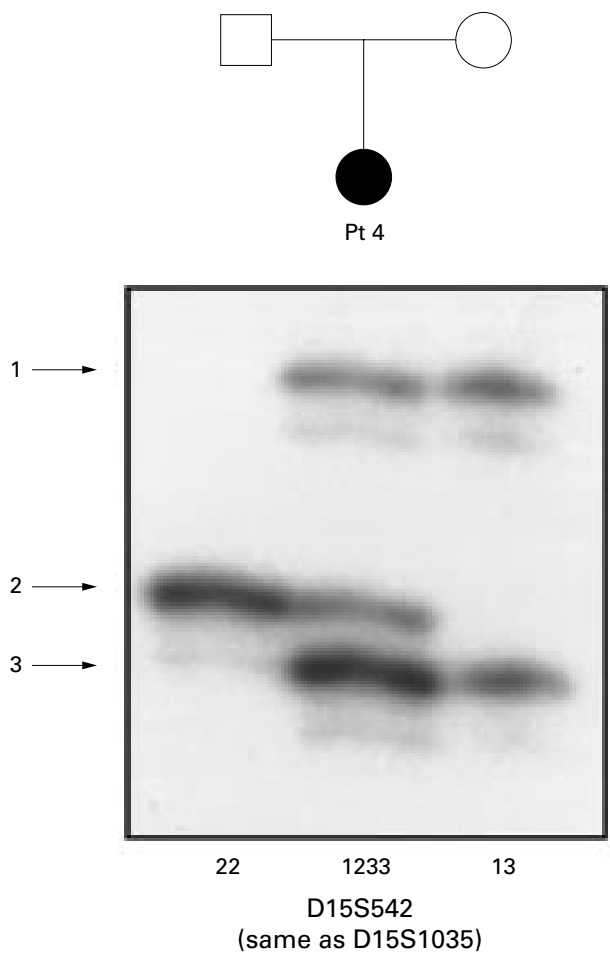

Figure 4 Microsatellite analysis at locus D15S1035 in family of patient (Pt) 1 (A) and at locus D15S542 in family of Pt 4 (B). The triplication is of paternal origin in patient 1 as determined by the presence of three paternal alleles and one maternal allele. Note that the intensity of allele 4 is higher than the same allele in the father, indicating that in patient 1 allele 4 is duplicated. In patient 4, the triplication is of maternal origin as indicated by the presence of three maternal alleles and one paternal allele. The increase of intensity of allele 3 in patient 4 indicates that this is the duplicated allele. 


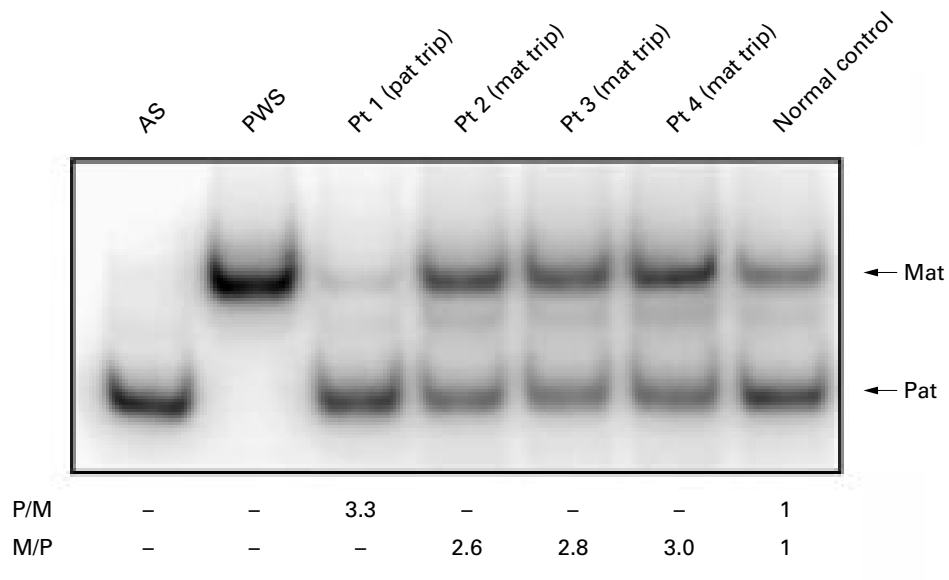

Figure 5 Methylation analysis of the CPG island at the 5' end of the SNRPN gene. In each lane the upper band (174 bp) is from the maternal chromosome and the lower band (100 bp) is from the paternal one. The Angelman syndrome patient AS with a deletion of the maternal 15q11-q13 chromosome shows only the paternal band, while the Prader-Willi patient PWS with a paternal deletion of the same region shows only the maternal band. Patient (Pt) 1 has a more intense paternal band that indicates paternal inheritance of the triplication $(P / M=3.3)$, while Pt 2,3 , and 4 show a more intense maternal band suggesting that the triplication is of maternal origin $(M / P=2.6$ in Pt 2, 2.8 in Pt 3, 3.0 in Pt 4). In the normal control, the intensity of the two bands is almost the same and it is used as a reference value. Further details can be found in the Methods section.

ORIENTATION OF THE TRIPLICATED SEGMENTS In all four patients, the orientation of the triplication was determined using two probes within the triplicated region, one located near the proximal boundary and one located $\sim 4 \mathrm{Mb}$ further distal. The proximal probes were c512 for patients 1,3 , and 4 , and D15S11 for patient 2. b150L13 was used as distal probe in all four patients. The positions of the probes used are shown in fig 1 . The results showed that the distances between the signals were not equal across the triplication (fig 3A): for c512 and D15S11 the middle signal was closer to the more distal signal than to the proximal, whereas for b150L13 the middle signal was closer to the proximal signal. These results indicate that the middle repeat is inverted in orientation with respect to the two flanking segments that are normally orientated. An ideogram of the abnormal chromosome with the orientation of the repeats is shown in fig $3 \mathrm{~B}$.

PARENTAL ORIGIN OF THE TRIPLICATIONS Molecular analysis of microsatellite polymorphisms within 15q11-q13 showed that patient 1 has three distinct alleles for S1035, S13, S1365, and GABRB3 polymorphisms. Analysis at locus S1035 shows that the patient inherited one allele from her mother and two alleles from her father, one of which is present in two copies, as shown by the higher intensity of allele 4 in the patient compared to the same allele in her father (fig 4A). At least three different markers were tested in the other patients: D15S113, GABRB3, and GABRA5 in patient 2; D15S18, D15S11, D15S13, D15S113, GABRB3, and D15S97 in patient 3; and D15S18, D15S1035, D15S11, D15S13, D15S113, GABRB3, and D15S97 in patient 4. For each informative marker, the patients inherited one paternal and two different maternal alleles, with one of the maternal alleles being present in two copies. An example is shown in fig $4 \mathrm{~B}$, where allele 3 of patient 4 is twice the intensity as the same allele in the mother.

These results indicate that for patient 1 the triplication is paternal in origin, while for patients 2-4 the triplications are maternal in origin.

\section{SNRPN METHYLATION AND EXPRESSION}

Methylation in exon 1 of $S N R P N$ was examined in all patients using methylation specific PCR (fig 5). The maternal allele gives rise to a $174 \mathrm{bp}$ band and the paternal allele to a $100 \mathrm{bp}$ band. A control subject with a normal karyotype was analysed to calculate the pat/mat and the mat/pat ratios in order to normalise the results obtained for our patients. DNA from patient 1 (paternal triplication) shows a paternal band approximately three times more intense than the maternal band, while in the three maternal triplication patients (2-4), the signal from the maternal allele is about three times more intense than that from the paternal allele. These findings confirm the presence of one copy of the maternal allele and three copies of the paternal alleles in patient 1 , and of one copy of the paternal allele and three copies of the maternal alleles in patients 2-4.

Normally, the SNRPN gene is expressed only from the paternal chromosome. ${ }^{17}$ In order to determine if the extra copies of the 15q11-q14 region influence the expression of this paternally expressed gene, the RNA from our patients was tested by northern blotting and compared to that from a normal control. As expected, SNRPN expression increased only in the patient who inherited the paternal triplication. In the three maternal triplications, the levels were similar to those of the normal control (fig 6). A low level of expression was observed in the PWS control consistent with published data that indicated SNRPN is $96-100 \%$ methylated from the maternal allele. ${ }^{34}$

\section{Discussion}

This work reports the clinical and molecular findings for four subjects with de novo interstitial triplications of the $15 \mathrm{q} 11-\mathrm{q} 14$ region. The clinical manifestations of the four patients are summarised in table 1 and compared with the other three known cases of triplication of the same region.

Molecular analysis shows that in patients 2, 3 , and 4 the triplication is maternal in origin. A maternal triplication in a case with mild features of AS was previously described by Schinzel et $a l^{4}$ More recently, Long et $a \bar{l}$ reported a patient with developmental delay who was found to have a small supernumerary inv dup(15) and an interstitial triplication of proximal 15q11-q13 maternal in origin. The absence of euchromatin from the PWS/AS critical region within the inv dup(15) suggests that the trip(15) is responsible for that patient's abnormal phenotype. Moreover, all the de novo supernumerary marker 15 chromosomes that include the PWS/AS critical region are maternal in origin ${ }^{843536}$ and are associated 
A
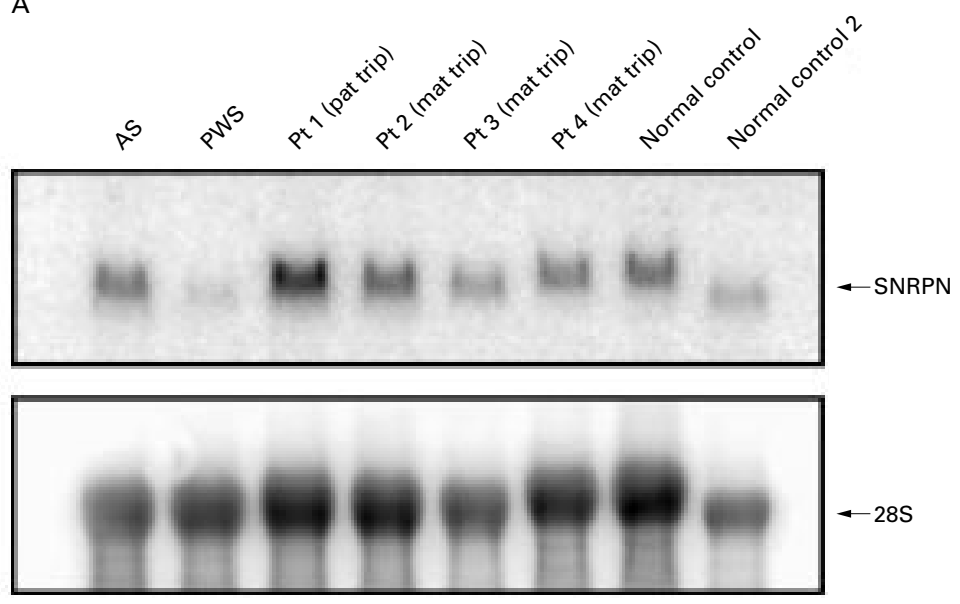

B

\begin{tabular}{|l|c|}
\hline Patient & $\begin{array}{c}\text { Relative SNRPN } \\
\text { expression }\end{array}$ \\
\hline AS & 1.2 \\
PWS & 0.2 \\
Pt 1 & 2.2 \\
Pt 2 & 1.2 \\
Pt 3 & 0.9 \\
Pt 4 & 0.9 \\
Normal controls & 1.0 \\
\hline
\end{tabular}

Figure 6 Expression of the SNRPN gene. (A) Autoradiograph of a gel loaded with $20 \mu \mathrm{g}$ of total RNA extracted from lymphoblastoid cell lines from each patient and hybridised sequentially with a cDNA probe for SNRPN and with an oligonucleotide specific for $28 S$ $r R N A$ to correct for RNA loading differences. (B) Relative SNRPN expression for each sample. Only in patient 1 (Pt 1), who has a paternal triplication, is the SNRPN expression more than two times increased compared to the normal controls. Patients 2, 3, and 4 (Pt 2, Pt 3,Pt 4) with a triplication of maternal origin have SNRPN RNA levels similar to the normal controls. SNRPN RNA levels were not different from the normal controls in a patient with Angelman syndrome (AS) with a deletion of the maternal 15q11-q13 chromosome, and almost absent in a patient with Prader-Willi syndrome (PWS) with a deletion of the same region on the paternal chromosome.

with moderate to severe mental retardation. ${ }^{822437}$ These observations indicate that maternal rearrangements of the 15q11-q13/ q14 region can be associated with an abnormal phenotype.

A paternal triplication of the 15q11-q13 region was previously found by Cassidy et $a l^{\beta}$ in a hypotonic, developmentally delayed child with non-specific findings. Patient 1 , described here, has a triplication of the 15q11-q14 region on the paternal chromosome that is associated with mental retardation, obesity, and cleft palate. These results indicate that paternal triplication of the PWS/AS critical region may also have phenotypic effects, unlike duplications that show a normal phenotype. ${ }^{219}$

By using the three markers D15S1019, D15S165, and D15S144, we have shown that the triplication involves two breakpoints located between D15S1019 and D15S165 (BP4) and between D15S165 and D15S144 (BP5) that are likely to represent the breakpoints for most large inv dup(15) chromosomes. ${ }^{11}$ Both $\mathrm{BP} 4$ and BP5 contain portions of the genomic duplication (duplicon) present in BP2 and
$\mathrm{BP} 3 \mathrm{~A} / 3 \mathrm{~B}^{16}$ (unpublished data) that are likely to be hotspots for recombination.

Intrachromosomal triplications of chromosome 15 seem to result from a common mechanism as indicated by the inverted orientation of the middle repeat found in our patients and in previously reported cases. ${ }^{45}$ Wang et $a l^{88}$ recently reviewed the published reports since 1993 and identified at least 11 cases of intrachromosomal triplication, affecting chromosomes $2 \mathrm{q}, 5 \mathrm{p}, 7 \mathrm{p}, 9 \mathrm{p}$, and $15 \mathrm{q}$, involving an inverted orientation of the middle repeat in all cases investigated. These authors proposed a mechanism of two $U$ type exchanges involving three chromatids, as previously described in Drosophila by Slizynska. ${ }^{39}$ For chromosome 15, this would include a $U$ type exchange in meiosis I between homologues at the distal breakpoint region and a second $U$ type exchange at the proximal breakpoint region between sister chromatids of a single homologue (see fig 4 in Wang et $a p^{\beta 8}$ ). This mechanism gives rise to a small inv dup(15), as was seen in the case of Long et $a l,{ }^{5}$ but may more often be lost, and a chromosome 15 which contains three sequentially arranged segments of which the first and third repeats are in direct orientation while the second one is inverted. Another possible mechanism of recombination was previously described by Schinzel et al, ${ }^{4}$ where the authors proposed that the first step in the formation of the triplication involves an unstable dicentric inv $\operatorname{dup}(15)$ (pter $\rightarrow$ q13::q13 $\rightarrow$ pter) chromosome of maternal origin that contains both a direct and an inverted repeat. Triplication would be the result of recombination between this broken chromosome and the remaining normal chromosome 15 followed by the loss of the supernumerary marker.

The phenotypic abnormalities associated with the chromosomal rearrangements of the 15q11-q14 region can be determined by alterations in the expression of the imprinted genes mapping within the PWS/AS critical region. At least five imprinted, paternally expressed genes have been localised to the centromeric end of the PWS/AS critical region, including $Z N F 127,{ }^{40} N D N,{ }^{41}$ MAGEL $2{ }^{42}$ SNURF/SNRPN, ${ }^{43}{ }^{44}$ and IPW. ${ }^{45} P A R-1$ and $P A R-5$ are paternally expressed sequences which remain poorly characterised. ${ }^{46} \mathrm{UBE} 3 \mathrm{~A}$ is preferentially expressed from the maternal chromosome in brain and is localised distally to the paternally expressed cluster of genes. ${ }^{47}$ The region also includes a cluster of three $\mathrm{GABA}_{\mathrm{A}}$ receptors with unclear imprinting status. ${ }^{48} 49$

In each patient we studied the methylation status of the $\mathrm{CpG}$ island located upstream of the SNRPN gene. ${ }^{46}$ Our results showed that the presence of the 15q11-q14 triplicated region does not interfere with SNRPN methylation status, maintaining hypomethylation on the paternal chromosome and hypermethylation on the maternal chromosome. Accordingly, $S N R P N$ RNA levels increased only in the patient with paternal triplication (patient 1), while in the three maternal triplication patients, SNRPN expression was normal. These results suggest that an alteration in the levels of SNRPN RNA may play a role in the 
pathogenesis of the phenotype of patient 1 . However, the expression of other imprinted and non-imprinted genes mapping in the $15 \mathrm{q} 11-\mathrm{q} 14$ region was not investigated in this study and probably also contributes to the abnormal phenotype observed in these patients.

Results presented in this paper suggest that a single, common mechanism gives rise to the proximal $15 \mathrm{q}$ triplications observed in our patients and additionally identify breakpoints in common with other chromosome 15 rearrangements. These data constitute an important contribution to our understanding of the nature and mechanism of formation of these chromosomal rearrangements, as well as the derivation and potential familial recurrence of AS, PWS, and pervasive developmental delay/ autism. Taken together, this information may aid in providing appropriate genetic counselling, especially in the context of prenatal diagnosis.

We would like to thank Dr L B K Herzing and Dr R J Leventer for critical reviewing of the manuscript and Dr J S Sutcliffe for providing the UBE3A FISH probe. This work was supported by NIH grant HD36111.

1 Ledbetter D, Ballabio A. molecular cytogenetics of contiguous gene syndromes: mechanism and consequences of gene
dosage imbalance. In: Scriver CR, Beaudet AL, Sly WS, Valle D, eds. The metabolic and molecular bases of inherited disease. New York: McGraw-Hill, 1995:811-39.

2 Browne CE, Dennis NR, Maher E, Long FL, Nicholson JC, Sillibourne J, Barber JC. Inherited interstitial duplications of proximal 15q: genotype-phenotype correlations. Am f of proximal 15q: genotype-phen

3 Cassidy S, Conroy J, Becker L, Schwartz S. Paternal triplication of 15q11-q13 in a hypotonic, developmentally delayed child without Prader-Willi or Angelman syndrome. Am ₹ Med Genet 1996;62:205-12.

4 Schinzel AA, Brecevic L, Bernasconi F, Binkert F, Berthet F, Wuilloud A, Robinson WP. Intrachromosomal triplication of 15q11-q13. F Med Genet 1994;31:798-803.

5 Long FL, Duckett DP, Billam LJ, Williams DK, Crolla JA. Triplication of $15 \mathrm{q} 11$-q13 with inv $\operatorname{dup}(15)$ in a female with developmental delay. F Med Genet 1998;35:425-8.

6 Horsthemke B, Maat-Kievit A, Sleegers E, van den Ouweland A, Buiting K, Lich C, Mollevanger P, Beverstock G, Gillessen-Kaesbach G, Schwanitz G. Familial translocations involving 15q11-q13 can give rise to interstitial deletions causing Prader-Willi or Angelman syndrome. $7 \mathrm{Med}$ Genet 1996;33:848-51.

7 Greger V, Knoll JH, Wagstaff J, Woolf E, Lieske P, Glatt H, Benn PA, Rosengren SS, Lalande M. Angelman syndrome associated with an inversion of chromosome 15q11.2q24.3. Am f Hum Genet 1997; 60:574-80.

8 Crolla J, Harvey J, Sitch F, Dennis N. Supernumerary marker 15 chromosome: a clinical, molecular and FISH approach to diagnosis and prognosis. Hum Genet 1995;95: 161-70.

9 Wandstrat AE, Leana-Cox J, Jenkins L, Schwartz S. Molecular cytogenetic evidence for a common breakpoint in the largest inverted duplications of chromosome 15. Am 7 Hum Genet 1998;62:925-36.

10 Christian SL, Bhatt NK, Martin SA, Sutcliffe JS, Kubota T, Huang B, Mutirangura A, Chinault AC, Beaudet AL, Ledbetter DH. Integrated YAC contig map of the Prader-Willi/ Angelman region on chromosome $15 \mathrm{q} 11-\mathrm{q} 13$ with average Angelman region on chromosome 15q11-q13 with

11 Robinson WP, Dutly F, Nicholls RD, Bernasconi F, Penaherrera M, Michaelis RC, Abeliovich D, Schinzel AA Penaherrera $M$, Michaelis RC, Abeliovich D, Schinzel AA.
The mechanisms involved in formation of deletions and The mechanisms involved in formation of deletions an
duplications of 15q11-q13. f Med Genet 1998;35:130-6.

12 Knoll JH, Nicholls RD, Magenis RE, Glatt K, Graham JM Jr, Kaplan L, Lalande M. Angelman syndrome: three molecular classes identified with chromosome 15q11q13-specific DNA markers. Am F Hum Genet 1990, 47:149-55

13 Kuwano A, Mutirangura A, Dittrich B, Buiting K, Horsthemke B, Saitoh S, Niikawa N, Ledbetter S, Greenberg F, Chinault A, Ledbetter D. Molecular dissection of the Prader-Willi/Angelman syndrome region (15q11-13) by YAC cloning and FISH analysis. Hum Mol Genet 1992;1:417-25.

14 Christian SL, Robinson WP, Huang B, Mutirangura A, Line MR, Nakao M, Surti U, Chakravarti A, Ledbetter DH Molecular characterization of two proximal deletion breakpoint regions in both Prader-Willi and Angelman syndrome patients. Am f Hum Genet 1995;57:40-8. 15 Huang B, Crolla JA, Christian SL, Wolf-Ledbetter ME, Macha ME, Papenhausen PN, Ledbetter DH. Refined molecular characterization of the breakpoints in sm

16 Christian SL, Fantes JA, Mewborn SK, Huang B, Ledbetter DH. Large genomic duplicons map to sites of instability in the Prader-Willi/Angelman syndrome chromosome region (15q11-q13). Hum Mol Genet 1999;8:1025-37.

17 Nicholls R, Saitoh S, Horsthemke B. Imprinting in PraderWilli and Angelman syndromes. Trends Genet 1998;14:194200.

18 Bundey S, Hardy C, Vickers S, Kilpatrick MW, Corbett JA. Duplication of the 15q11-13 region in a patient with autism, epilepsy and ataxia. Dev Med Child Nerol 1994;36: 736-42.

19 Cook EH Jr, Lindgren V, Leventhal BL, Courchesne R, Lincoln A, Shulman C, Lord C, Courchesne E. Autism or atypical autism in maternally but not paternally derived proximal 15q duplication. Am $\mathcal{F}$ Hum Genet 1997;60:92834 .

20 Schroer RJ, Phelan MC, Michaelis RC, Crawford EC, Skinner SA, Cuccaro M, Simensen RJ, Bishop J, Skinner C, Fender D, Stevenson RE. Autism and maternally derived aberrations of chromosome 15q. Am f Med Genet 1998;76: 327-36.

21 Repetto G, White L, Bader P, Johnson D, Knoll J. Interstitial duplications of chromosome region 15q11q13: clinical and

2 Webb T. Inv dup (15) f Med Genet 1994;31:585-94.

23 Schinzel A. Catalogue of unbalanced chromosome aberrations in man. Berlin: de Gruyter, 1984.

24 Robinson WP, Binkert F, Gine R, Vazquez C, Muller W, Rosenkranz W, Schinzel A. Clinical and molecular analysis of five inv dup(15) patients. Eur f Hum Genet 1993;1:3750 .

25 Pettigrew AL, Gollin SM, Greenberg F, Riccardi VM, Ledbetter DH. Duplication of proximal $15 \mathrm{q}$ as a cause of Prader-Willi syndrome. Am f Med Genet 1987;28:791-802.

26 Clayton-Smith J, Webb T, Cheng XJ, Pembrey ME, Malcolm S. Duplication of chromosome 15 in the region $15 \mathrm{q} 11-13$ in a patient with developmental delay and ataxia
with similarities to Angelman syndrome. $\mathcal{f}$ Med Genet 1993;30:529-31.

27 Chong SS, Pack SD, Roschke AV, Tanigami A, Carrozzo R, Smith AC, Dobyns WB, Ledbetter DH. A revision of the lissencephaly and Miller-Dieker syndrome critical regions in chromosome 17p13.3. Hum Mol Genet 1997;6:147-55.

28 Sutcliffe JS, Jiang YH, Galijaard RJ, Matsuura T, Fang P, Kubota T, Christian SL, Bressler J, Cattanach B, Ledbetter $\mathrm{DH}$, Beaudet AL. The E6-Ap ubiquitin-protein ligase syndrome critical region. Genome Res 1997;7:368-77.

29 Mutirangura A, Greenberg F, Butler MG, Malcolm S, Nicholls RD, Chakravarti A, Ledbetter DH. Multiplex PCR of three dinucleotide repeats in the Prader-Willi/ Angelman critical region (15q11-q13): molecular diagnosis and mechanism of uniparental disomy. Hum Mol Genet 1993;2:143-51.

30 Kubota T, Das S, Christian SL, Baylin SB, Herman JG, Ledbetter DH. Methylation-specific PCR simplifies imprinting analysis. Nat Genet 1997;16:16-17.

31 Glenn CC, Saitoh S, Jong MT, Filbrandt MM, Surti U, Driscoll DJ, Nicholls RD. Gene structure, DNA methylation, and imprinted expression of the human SNRPN gene. Am ₹ Hum Genet 1996;58:335-46.

32 Feinberg AP, Vogelstein B. A technique for radiolabelling DNA restriction endonuclease fragments to high specific activity. Anal Biochem 1984;137:266-7.

33 Barbu V, Dautry F. Northern blot normalization with a $28 \mathrm{~S}$ rRNA oligonucleotide probe. Nucleic Acids Res 1989;17: 7115

34 Zeschnigk M, Schmitz B, Dittrich B, Buiting K, Horsthemke B, Doerfler W. Imprinted segments in the human genome: different DNA methylation patterns in the Prader-Willi/Angelman syndrome region as determined by the genomic sequencing method. Hum Mol Genet 1997;6: 387-95.

35 Wisniewski L, Hassold T, Heffelfinger J, Higgins JV. Cytogenetic and clinical studies in five cases of inv dup(15). Hum Genet 1979;50:259-70.

36 Maraschio P, Zuffardi O, Bernardi F, Bozzola M, De Paoli C, Fonatsch C, Flatz SD, Ghersini L, Gimelli G, Loi M, Lorini R, Peretti D, Poloni L, Tonetti D, Vanni R, Zamboni Lorini R, Peretti D, Poloni L, Tonetti D, Vanni R, Zamboni
G. Preferential maternal derivation in inv $\operatorname{dup}(15)$ : analysis of eight new cases. Hum Genet 1981;57:345-50.

37 Leana-Cox J, Jenkins L, Palmer CG, Plattner R, Sheppard L, Flejter WL, Zackowski J, Tsien F, Schwartz S. Molecular cytogenetic analysis of inv dup (15) chromosomes, using probes specific for the Prader-Willi/Angelman syndrome region: clinical implications. Am $f$ Hum Genet 1994;54: $748-56$

38 Wang J, Reddy KS, Wang E, Halderman L, Morgan BL, Lachman RS, Lin HJ, Cornford ME. Intrachromosomal triplication of $2 \mathrm{q} 11.2-\mathrm{q} 21$ in a severely malformed infant: case report and review of triplications and their possible mechanism. Am f Med Genet 1999;82:312-17.

39 Slizynska H. Triplications and the problem of nonhomologous crossing-over. Genet Res 1968;11:201-8.

40 Jong M, Gray T, Ji Y, Glenn C, Saitoh S, Driscoll D, Nicholls R. A novel imprinted gene, encoding a RING zinc-finger protein, and overlapping antisense transcript in he Prader-Willi 1999;8:783-93. 
41 Jay P, Rougeulle C, Massacrier A, Moncla A, Mattei M, Malzac P, Roeckel N, Taviaux S, Lefranc J, Cau P, Berta P, Lalande M, Muscatelli F. The human necdin gene, NDN, is maternally imprinted and located in the Prader-Will syndrome chromosomal region. Nat Genet 1997;17:35761.

42 Boccaccio I, Glatt-Deeley H, Watrin F, Roeckel N, Lalande M, Muscatelli F. The human MAGEL2 gene and its mouse homologue are paternally expressed and mapped to the Prader-Willi region. Hum Mol Genet 1999; 8:2497-505.

43 Ozcelik T, Leff S, Robinson W, Donlon T, Lalande M, Sanprotein polypeptid, Francke U. Small mectea Prader-Willi syndrome critical region. Nat Genet 1992;2: 265-9.

44 Gray TA, Saitoh S, Nicholls RD. An imprinted, mammalian bicistronic transcript encodes two independent proteins. Proc Natl Acad Sci USA 1999;96:5616-21.
45 Wevrick R, Kerns JA, Francke U. Identification of a novel paternally expressed gene in the Prader-Willi syndrome

46 Sutcliffe JS, Nakao M, Christian S, Orstavik KH, Tommerup N, Ledbetter DH, Beaudet AL. Deletions of a differentially methylated $\mathrm{CpG}$ island at the SNRPN gene define a putative imprinting control region. Nat Genet 1994;8:52-8.

47 Rougeulle C, Glatt H, Lalande M. The Angelman syndrome candidate gene, UBE3A/E6-AP, is imprinted in brain. Nat Genet 1997;17:14-15.

48 Meguro M, Mitsuya K, Sui H, Shigenami K, Kugoh H, Nakao M, Oshimura $M$. Evidence for uniparental, paternal expression of the human GABAA receptor subunit genes, using microcell-mediated chromosome transfer. Hum $\mathrm{Mol}$ Genet 1997;6:2127-33.

49 Gabriel JM, Higgins MJ, Gebuhr TC, Shows TB, Saitoh S, Nicholls RD. A model system to study genomic imprinting
of human genes. Proc Natl Acad Sci USA 1998;95:14857-62. 